Gynäkologische Onkologie

Uwe Ulrich (Hrsg.) 



\section{Gynäkologische Onkologie}

Ein Kompendium für die Klinik

Herausgegeben

von Uwe Ulrich

DE GRUYTER 
Herausgeber

Prof. Dr. med. Uwe Ulrich

Klinik für Gynäkologie und Geburtshilfe

Martin-Luther-Krankenhaus

Caspar-Theyß-Str. 27-31

14193 Berlin

Das Buch enthält 114 Abbildungen und 63 Tabellen.

Einbandabbildung: MRT eines Leiomyosarkoms bei einer 43-jährigen Patientin

(Dank an Priv.-Doz. Dr. E. Lopez Hänninen, Martin-Luther-Krankenhaus, Berlin, für die Abb.)

ISBN 978-3-11-021625-7

e-ISBN 978-3-11-021626-4

Library of Congress Cataloging-in-Publication Data

A CIP catalogue record for this book is available from the Library of Congress.

Bibliografische Information der Deutschen Nationalbibliothek

Die Deutsche Nationalbibliothek verzeichnet diese Publikation in der Deutschen

Nationalbibliografie; detaillierte bibliografische Daten sind im Internet

über http://dnb.dnb.de abrufbar.

(c) 2013 Walter de Gruyter GmbH \& Co. KG, Berlin/Boston

Der Verlag hat für die Wiedergabe aller in diesem Buch enthaltenen Informationen (Programme, Verfahren, Mengen, Dosierungen, Applikationen etc.) mit Autoren bzw. Herausgebern große Mühe darauf verwandt, diese Angaben genau entsprechend dem Wissensstand bei Fertigstellung des Werkes abzudrucken. Trotz sorgfältiger Manuskriptherstellung und Korrektur des Satzes können Fehler nicht ganz ausgeschlossen werden. Autoren bzw. Herausgeber und Verlag übernehmen infolgedessen keine Verantwortung und keine daraus folgende oder sonstige Haftung, die auf irgendeine Art aus der Benutzung der in dem Werk enthaltenen Informationen oder Teilen davon entsteht.

Die Wiedergabe der Gebrauchsnamen, Handelsnamen, Warenbezeichnungen und dergleichen in diesem Buch berechtigt nicht zu der Annahme, dass solche Namen ohne weiteres von jedermann benutzt werden dürfen. Vielmehr handelt es sich häufig um gesetzlich geschützte, eingetragene Warenzeichen, auch wenn sie nicht eigens als solche gekennzeichnet sind.

Satz: Beltz Bad Langensalza GmbH, Bad Langensalza

Druck: Hubert \& Co., Göttingen

@ Gedruckt auf säurefreiem Papier

Printed in Germany

www.degruyter.com 
Unseren Patientinnen 
„Ich sehe einen solchen Lauf der Welt:

Das Übel tritt einher aus allen Klüften,

Im Innern eines jeden Menschen hält

Es haus und schwingt sich nieder aus den Lüften:

Auf jeden lauert eigene Gefahr,

Und nicht die Bäume mit den starken Düften

Und nicht die Luft der Berge, kühl und klar,

Verscheuchen das, auch nicht der Rand der See.

Denn eingeboren ist ihr eignes Weh

Den Menschen: ja, indem ich es so nenne,

Verschleir ich schon die volle Zwillingsnäh,

Mit ders dem Sein verwachsen ist, und trenne,

Was nur ein Ding: denn lebend sterben wir.

Für Leib und Seele, wie ich sie erkenne,

Gilt dieses Wort, für Baum und Mensch und Tier.

Und hier ..."

"Der Arzt" in „Das kleine Welttheater oder die Glücklichen“, 1897

(Hugo v. Hoffmannsthal, Die Gedichte und kleinen Dramen,

Insel Verlag, Leipzig, 1923) 